\title{
Family Medicine Research That Provides Compelling, Urgent Data to Improve Patient Care
}

\author{
Marjorie A. Bowman, MD, MPA, Dean A. Seebusen, MD, MPH, and \\ Anne Victoria Neale, $\mathrm{PhD}, \mathrm{MPH}$
}

Herein is positive, mixed, and negative news-albeit all useful—on family medicine topics. The time to depression remission can be dramatically reduced. There is compelling evidence on how to improve medication reconciliation. There is a major underestimated determinant of the length of intrauterine device use. Data on the convoluted nature of the International Classification of Diseases, 10th Revision, transition could cause heart sink for doctors. Another article notes how family physicians can improve the usability of electronic health records by working with vendors. Targeting abstinence for patients with alcohol dependency and daily use may help. Charlson comorbidity scores plus a polypharmacy measure are useful to estimate readmission risk. This issue also includes excellent reviews on pre-exposure prophylaxis for HIV prevention and breast milk oversupply. The Robert Graham Center provides data on the types of medical professionals working with family physicians in their offices. See the related commentary on page 4 by Rosenthal for a discussion on the patient-centered medical home articles also published in this issue. (J Am Board Fam Med 2016;29:1-3.)

For patients with depression, it is not just remission that matters, but the time to reach remission. In a fascinating and important article, Garrison et $\mathrm{al}^{1}$ find substantial differences in the amount of time it took to reach remission among patients with depression treated with collaborative care versus usual care. Much of the previous literature emphasizes remission itself as the primary outcome. This article provides dramatic results, that is, more than a year difference in time to remission for collaborative care patients compared with those without collaborative care. All were diagnosed with depression or dysthymia; all were treated with antidepressants. The Robert Graham Center also presents some useful data that are pertinent to the collaborative treatment of depression. While family physicians frequently work with nurse practitioners and/or physicians assistants, ${ }^{2}$ the number of family physicians working directly in the office with behavioral

Conflict of interest: The authors are editors of the $7 A B F M$.

\footnotetext{
See Related Commentary on Page 4.
}

specialists or psychiatrists is much lower at about one fifth of family physicians. To increase collaborative mental health care, these numbers need to increase. The recent fournal of the American Board of Family Medicine supplement on integrated care $^{3}$ provides related helpful information.

Health literacy is known to be important in health outcomes. Health care providers often work to overcome literacy issues, but often without much guidance or certainty of improved outcomes. The Agency for Health care Research and Quality has a health literacy toolkit that Weiss et $\mathrm{al}^{4}$ tested for medication reconciliation in 2 practices. The primary implemented items were not particularly time consuming, and the results were impressive: substantially more drug therapy problems were identified and revisions undertaken. For those not using the toolkit methods, it's time to start!

In another persuasive report, Chang et $\mathrm{al}^{5}$ find that patients who initiate a discussion of intrauterine devices (IUDs) keep their IUDs much longer than do patients for whom the physician introduced the idea of an IUD. The difference among this population was more than a year! The physicianinitiated IUDs were removed at 6 months, on av- 
erage. Follow-up research is needed to identify interventions to improve these numbers.

Our readers in the United States are now coding visits using the International Classification of Diseases, 10th Revision (ICD-10). And, by now, they may well know how easy or tough the new codes are to use. Yet, these same readers are unlikely to know how well they are doing, because reimbursement rates have not yet been well tested. Boyd and coauthors ${ }^{6}$ provide a great service by estimating the inherent coding difficulties embedded in the change from International Classification of Diseases, 9th Revision (ICD-9), to ICD-10. About a quarter of the diagnosis code transitions from ICD-9 to ICD-10 were found to be convoluted, and a third of the payments were convolutedexactly what many physicians fear. A quarter of diagnoses is a large number any day, and could actually mean at least one diagnosis for most patients seen. One third of payments is also a huge figure. The impact on our ability to compare former with current data regarding our quality of care systems or research could easily be as large. The authors provide some estimates of transition costs, as well as the impacts in other countries, but not an answer to the overall value (dollar or otherwise) of the transition to ICD-10.

It is possible for family physicians to assist in improving electronic health records (EHRs). After interviewing EHR vendors, Olayiwola et $\mathrm{al}^{7}$ provide 6 strategies for immediate implementationfor the sake of all US physicians! Some of this effort should clearly go toward EHR assistance for ICD-10 coding.

Alcohol dependence is a chronic disorder frequently encountered among family medicine patients. Long-term, repeated, multifaceted efforts often are necessary for people with alcohol dependence to stop or substantially reduce their alcohol intake and, by doing so, their risks for bad outcomes. In the report from Berger et al, ${ }^{8}$ patients did not drink on $\sim 80 \%$ of days for 3 months after treatment. Specifically for those who drank daily, the goal of abstinence was associated with better outcomes over 3 months. Daily drinkers seemed to have an easier time being abstinent than they did cutting the amount they drank in any one day, suggesting a triggering or reinforcing effect of any alcohol intake. Most patient change occurred in the first 2 weeks and then was maintained. A goal of abstinence versus reduction was selected by the patient, without specific direction. This study suggests that we should help daily drinkers choose an abstinence goal. Keeping the long-term goal in mind is necessary to help understand that relapses are a part of the trajectory to long-term health and are to be expected.

In other clinical research, Logue et $\mathrm{al}^{9}$ provide evidence that supports the concurrent use of the Charlson comorbidity index with a polypharmacy score to improve the prediction of hospital readmissions. Trimeloni and Spencer ${ }^{10}$ present tactics to deal with an under-expected, understudied, and under-discussed problem: breast milk oversupply. An excellent review on preexposure prophylaxis for HIV prevention is authored by Conniff and Evensen. ${ }^{11}$ Ledford et al ${ }^{12}$ investigate the outcome of implementing computed tomography for reducing lung cancer mortality in a community hospital. The multiple articles on patient-centered medical homes ${ }^{13-20}$ are separately discussed by Thomas Rosenthal, who wrote the classic patient-centered medical home article, one of the most cited and read articles from the Fournal of the American Board of Family Medicine. ${ }^{21}$

\section{References}

1. Garrison GM, Angstman KB, O'Connor S, Williams MD, Lineberry TW. Time to remission for depression with collaborative care management $(\mathrm{CCM})$ in primary care. J Am Board Fam Med 2016;29:10-17.

2. Bazemore A, Wingrove P, Peterson L, Petterson S. The diversity of providers on the family medicine team. J Am Board Fam Med 2016;29:8-9.

3. Advancing care together by integrating behavioral health and primary care. J Am Board Fam Med 2015;28(Supplement 1):S1-110.

4. Weiss BD, Brega AG, LeBlanc WG, et al. Improving the effectiveness of medication review: guidance from the health literacy universal precautions toolkit. J Am Board Fam Med 2016;29:18-23.

5. Chang T, Moniz MH, Plegue MA, Sage Shaffer K, Vance H, Gold KJ. Patient or clinician: duration of use of intrauterine devices based on who initiated discussion of placement. J Am Board Fam Med 2016; 29:24-8.

6. Grief SN, Patel J, Kochendorfer KM, et al. Simulation of ICD-9 to ICD-10-CM transition for family medicine: simple or convoluted? J Am Board Fam Med 2016;29:29-36.

7. Olayiwola JN, Rubin A, Slomoff T, Woldeyesus T, Willard-Grace R. Strategies for primary care stakeholders to improve electronic health records (EHRs). J Am Board Fam Med 2016;29:126-34. 
8. Berger L, Brondino M, Fisher M, Gwyther R, Garbutt JC. Alcohol use disorder treatment: the association of pretreatment use and the role of drinking goal. J Am Board Fam Med 2016;29: 37-49.

9. Logue E, Smucker W, Regan C. Admission data predict high hospital readmission risk. J Am Board Fam Med 2016;29:50-9.

10. Trimeloni L, Spencer J. Diagnosis and management of breast milk oversupply. J Am Board Fam Med 2016;29:139-42.

11. Conniff J, Evensen A. Preexposure prophylaxis (PrEP) for HIV prevention: the primary care perspective. J Am Board Fam Med 2016;29:143-51.

12. Ledford CJW, Gawrys BL, Wall JL, Saas PD, Seehusen DA. Translating new lung cancer screening guidelines into practice: the experience of one community hospital. J Am Board Fam Med 2016;29: 152-5.

13. Khanna N, Shaya FT, Chirikov VV, Sharp D, Steffen B. Impact of case mix severity on quality improvement in a patient-centered medical home $(\mathrm{PCMH})$ in the Maryland multi-payor program. J Am Board Fam Med 2016;29:116-125.

14. Harder VS, Krulewitz J, Jones C, Wasserman RC, Shaw JS. Effects of patient-centered medical home transformation on child patient experience. J Am Board Fam Med 2016;29:60-8.
15. Halladay JR, Mottus K, Reiter K, et al. The cost to successfully apply for level 3 medical home recognition. J Am Board Fam Med 2016;29:69-77.

16. Kano M, Silva-Banuelos AR, Sturm R, Willging CE. Stakeholders' recommendations to improve patientcentered "LGBTQ" primary care in rural and multicultural practices. J Am Board Fam Med 2016;29: 156-60.

17. Bodenheimer T, Willard-Grace R. Teamlets in primary care: enhancing the patient and clinician experience. J Am Board Fam Med 2016;29:135-8.

18. Loskutova NY, Tsai AG, Fisher EB. Patient navigators connecting patients to community resources to improve diabetes outcomes. J Am Board Fam Med 2016;29:78-89.

19. Friedman A, Howard J, Shaw EK, Cohen DJ, Shahidi L, Ferrante JM. Facilitators and barriers to care coordination in patient-centered medical homes (PCMHs) from coordinators' perspectives. J Am Board Fam Med 2016;29:90-101.

20. Kwan BM, Sills MR, Graham D, et al. Stakeholder engagement in a patient-reported outcomes (PRO) measure implementation: a report from the SAFTINet practice-based research network (PBRN). J Am Board Fam Med 2016;29:102-15.

21. Rosenthal TC. The medical home: growing evidence to support a new approach to primary care. J Am Board Fam Med 2008;21:427-40. 